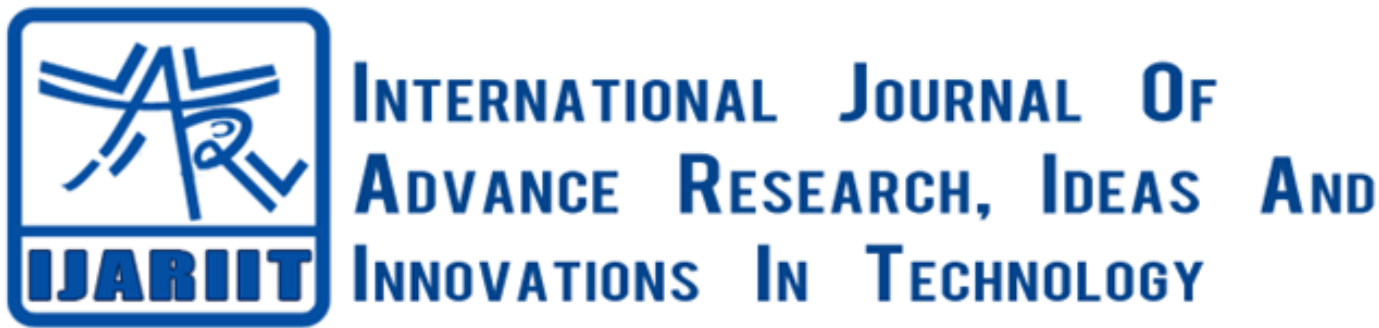

\author{
ISSN: 2454-132X \\ Impact factor: $\mathbf{6 . 0 7 8}$ \\ (Volume 6, Issue 5) \\ Available online at: $\underline{w w w . i j a r i i t . c o m}$
}

\title{
Strategies for integrating Open Access Resources (OAR) into libraries collections: A study
}

\author{
Isaac Echezonam Anyira \\ anyiraisaac@gmail.com \\ Delta State Polytechnic, Ogwashi-Ukwu, \\ Nigeria
}

\author{
Obiora Kingsley Udem \\ ok.udem@unizik.edu.ng \\ Nnamdi Azikiwe University, Awka, \\ Nigeria
}

\author{
Lucky Njoeteni \\ luckynjoeteni20@yahoo.com \\ Delta State Polytechnic, Ogwashi-Ukwu, \\ Nigeria
}

\begin{abstract}
The study's general purpose is to assist both management and collection development practitioners in adopting appropriate strategies for integrating $\mathrm{OA}$ materials into libraries collections. The study was designed to specifically examine the challenges to the integration of $O A R$ into libraries collections and to explore relevant strategies for the integration. The study utilized an online survey questionnaire sent to Seventy-Eight collections development staff drawn from academic libraries, Library Boards, and special libraries for completion. Sixty-Two (62) however, were completed and returned. This implies $79.4 \%$ return rate. All the respondents surveyed are members of the Nigerian Library Association (NLA), and are certified by the Librarians Registration Council of Nigeria (LRCN). The respondents were drawn from Federal university Libraries (7), State university libraries (6), private university libraries (22), federal polytechnic libraries (5), state polytechnic libraries (12), college libraries (5), special libraries (2), library boards (3). The survey instrument included Eleven (11) items. Data were analyzed using graphical charts. The findings indicate that majority of the library do not acquire OAR, but have plans to make them part of their regular library acquisition workflows; majority of them strongly agree that collection development policy is key to OAR integration, but they don't have the document for now, neither are their staff trained to manage $O A$ effectively. Their major challenge to OAR integration include poor electricity supply, lack of knowledge and skills required for OA integration, and lack of support from the head librarian, lack of collection development policy document. The recommendations include that collection development policy should be put in place; library staff should be equipped with relevant skills through training and retraining; libraries should rather than purchasing expensive books and journals download OAR relevant to them, process them and make them available to their users as part of their collections; Libraries should be provided with uninterrupted fast speed internet access and power supply from solar power.
\end{abstract}

Keywords: Acquisition, Collection development, Integration, Library collections, Open Access Resources.

\section{INTRODUCTION}

There are overwhelming opportunities available to libraries in the $21^{\text {st }}$ century to develop quality, and current collection to meet the ever-increasing needs of their users rather than solely rely on print or subscription-based materials. This opportunity is embedded in open access resources (OAR) integration into the library conventional collection. This type of active collection building adds ever increasing value to the library collection as well as provides exciting discovery of quality materials for library users. OAR can leverage collection development far beyond the norms of traditional library collection development practice. Collection development for libraries in this current dispensation depends largely on the World Wide Web.

Prior to the emergence of OAR, one of the greatest challenges of librarians is the problem of satisfying users' needs with ob solete and grossly inadequate information resources borne out of harsh economic conditions. There is no gain-saying that Nigerian libraries are grossly underfunded. Yet, there are more foreign literatures in all our libraries than local materials. Anyira and Idubor (2018) posited that these foreign literatures were acquired with foreign currencies and at very exorbitant prices. The exchange rate is another limitation that places these materials beyond the rich of our libraries. In addition to these, the library is further faced with the challenge of budgetary cuts and gross underfunding and the revenue generated from library charges is inadequate to acquire relevant resources (Anyira and Idubor, 2018). Interlibrary cooperation has remained ineffective as libraries cannot share what they do not have. Form our professional experiences and observations, many Nigerian libraries which are supposed to be lenders of information have become the greatest borrowers of information resources in order to secure accreditation for academic programmes of their parent institutions. What then is the way out? Open Access Resources (OAR) is the bailout option for our libraries. Since the early 2000's when OA was introduced in Nigeria, the availability, relevance, currency and adequacy of 


\section{Anyira Isaac Echezonam, et al.; International Journal of Advance Research, Ideas and Innovations in Technology}

information resources have been greatly enhanced in many Nigerian libraries (Anyira and Idubor, 2018). According to Anyira and Idubor (2019), OA has eased the effect of acute information shortfall that appears to be a normalcy in many of our libraries.

However, OAR came with its own peculiar challenge as well. The challenge with OA resources in libraries is multifaceted even though most libraries have embraced them. Some of these challenges are about lack of consensus of what constitutes open access (Anyira and Idubor, 2019), including understanding the main "colours" green, gold and platinum etc. other challenges associated with OAR are those associated with integrating OAR into library mainstream collection (International Federation of Library Associations and Institutions (IFLA), 2020).

It is worthy of note that the International Federation of Library Associations and Institutions (IFLA) scheduled to hold the IFLA World Library and Information Congress, in Dublin, Ireland, this August from $15^{\text {th }}$ to $21^{\text {st }}, 2020$, primarily to come up with strategies to integrate OAR into collections development workflows. According to IFLA (2020) "As more and more resources are available open access (OA), libraries face new challenges. We would like to start from a holistic understanding of the challenges about making open access material a part of the collection development workflow".

\subsection{Objectives}

The study's general purpose is to assist both management and collection development practitioners in adopting appropriate strategies for integrating OA materials into their libraries' collections. The specific objectives are:

- To examine practicable strategies for integrating OA materials into libraries' collections.

- To investigate the challenges to the integration of OA materials into libraries' collections.

- To recommend implementable solutions to the challenges.

\subsection{Research Questions}

- What are the strategies for integrating OA materials into libraries' collections?

- What are the challenges to the integration of OA materials into libraries' collections?

\section{LITERATURE REVIEW}

Budapest Open Access Initiative (2002) defined open access as a literature that is freely accessible online which scholars give to the world without expectation of payment. They include materials that are freely available on the public internet, permitting any user to read, download, copy, distribute, print, search, or link to the full texts of these articles, crawl them for indexing, pass them as data to software, or use them for any other lawful purpose, without financial, legal, or technical barriers other than those inseparable from gaining access to the internet itself. The only constraint on reproduction and distribution, and the only role for copyright in this domain, should be to give authors control over the integrity of their work and the right to be properly acknowledged and cited (Budapest Open Access Initiative, 2002). In an attempt to understand how "open" is "open access?", Anyira and Idubor (2018) observed that open access is free for the end users but it does not remove the cost of producing and publishing academic research. They noted that the cost model of OA, is known as the open access "Colour or Business model" (Suber, 2003; Anyira and Idubor, 2018). Then, Gent University (2020), Himmelstein, D., Romero, A., Levernier, J. (2018), explained the different colours of OA as:

- Gold: requires payment of article processing charge (APC) by authors or their sponsors, the article becomes freely available at the publication date and is published under the most permissive copyright license (CC-BY). Some funders like UKRI, COAF and Wellcome Trust provide additional pots of money (block grants) to support their researchers in making research outputs open access via gold route.

- Green: no payment required, authors deposit accepted version of their manuscript (not a publisher version) in Institutional Repository ensuring its discoverability, but there is usually delay in making the manuscript accessible (embargo period). The length of embargo period is specified by the publisher/journal. The pre-prints and post prints deposited at the researcher's institutional repository.

- Bronze: In the Bronze model no Open Access Fee is paid but the publisher chooses to make a publication freely available to read.

- Platinum/Diamond: In the Platinum or Diamond routes the authors, institutions, or funders do not pay an Open Access Fee and the reader does not pay to read. In effect, this is a 'publisher-pays' model and is usually offered by university presses where the costs of publication are subsumed within existing budgets and regarded as part of the mission of a university. Platinum/Diamond is an excellent model for Open Access, but it is highly unlikely that it could replace the scale of commercial scholarly publishers in a reasonable timeframe (Suber, 2003).

- Hybrid: A subscription journal in which the author is permitted to make an article available on an Open Access basis on payment of a fee after paying the publishing charges.

- Black: A publication made open access illegally or through hacking (e.g. via Sci-Hub) (Himmelstein, D., Romero, A., Levernier, J., 2018).

Increasingly, the Association of European Research Libraries (2019) has identified certain library activities that must be performed for effective integration of OA. These include the making of OA books part of the regular library acquisition workflows, indexing relevant OA titles in the library catalogues and discovery systems to ensure the end users can find them within the library holdings (collection development and cataloguing activities). Also, the library must put in place an OA policy document that supports OA integration (Association of European Research Libraries, 2019). Other activities include the provision of opportunities for staff to develop skills related to publishing, copyright, OA business models and metadata standards (Association of European Research Libraries, 2019). 


\section{Anyira Isaac Echezonam, et al.; International Journal of Advance Research, Ideas and Innovations in Technology}

The challenges to effective integration however are enormous. According to Anyira \& Idubor (2018) the challenges to OA integration to include lack of awareness, lack of a well written collection development policy that includes innovative technologies as part of library collections, unwillingness or resistance on the part of the librarians to embrace change, poor internet access/ low bandwidths, lack of knowledge and skills required for OA integration, lack of management support for improved library services.

\section{METHODOLOGY}

The survey method was used for the study. An online survey was sent to Seventy-Eight collections development staff of academic libraries, Library Boards, and special libraries for completion. Sixty-Two (62) however, were completed and returned. This implies $79.4 \%$ return rate. All the respondents surveyed are members of the Nigerian Library Association (NLA), and are certified by the Librarians Registration Council of Nigeria (LRCN). The respondents were drawn from Federal university Libraries (7), State university libraries (6), private university libraries (22), federal polytechnic libraries (5), state polytechnic libraries (12), college libraries (5), special libraries (2), library boards (3). The survey included Eleven (11) questionnaire items. Data were analyzed using graphical charts.

\section{DATA ANALYSIS AND RESULTS}

Chart 1: Do you "acquire" open access resources in your library?

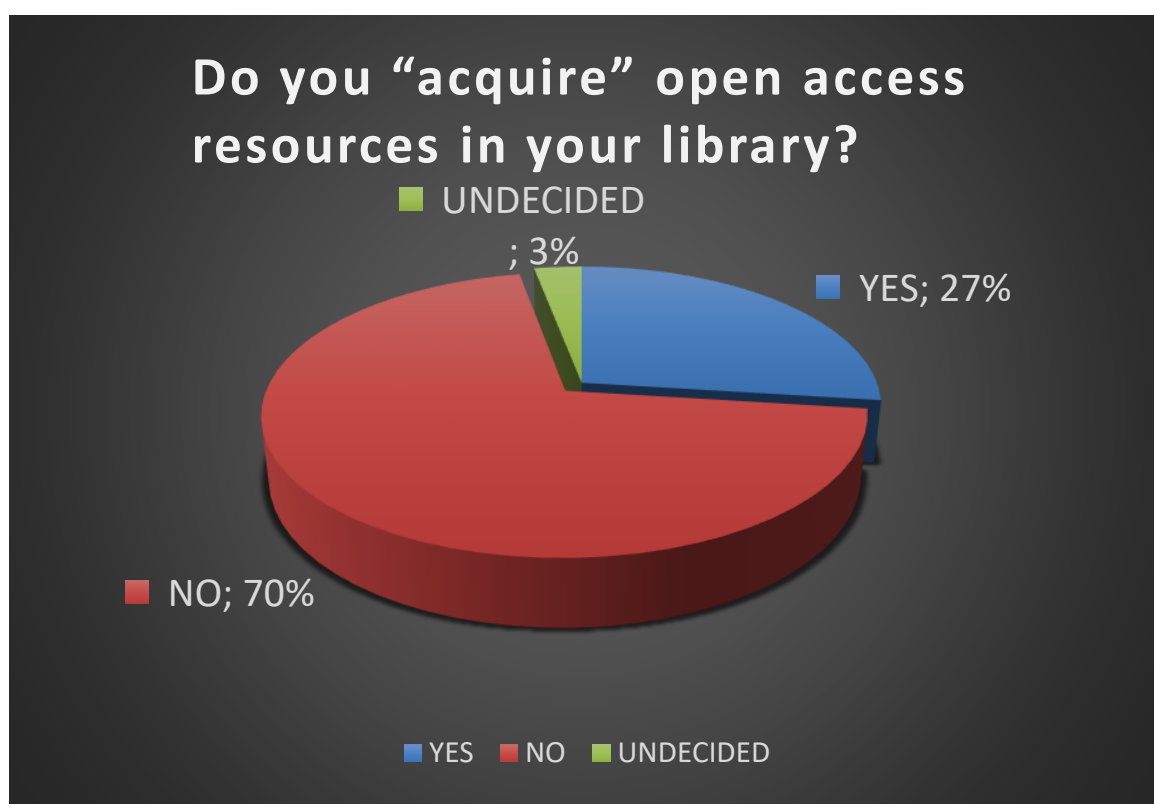

The result obtained shows that $70 \%$ of the respondents said that their library does not acquire OAR; $27 \%$ said they acquire, while $3 \%$ are undecided.

Chart 2: Does your library have plans to make OA part of the regular library acquisition workflows?

\section{Does your library have plans to make OA part of the regular library acquisition workflows?}

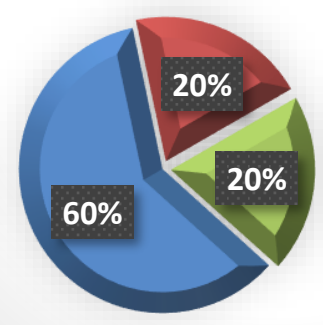

- YES

$\square$ NO

$\square$ UNDECIDED

The response gotten from the respondents as to whether their libraries have plans to make OA part of their regular library acquisition workflows indicate that $60 \%$ said Yes, $20 \%$ respectively answered No and Undecided respectively. 
Chart 3: Do you include open access materials in your accession register along with conventional library materials?

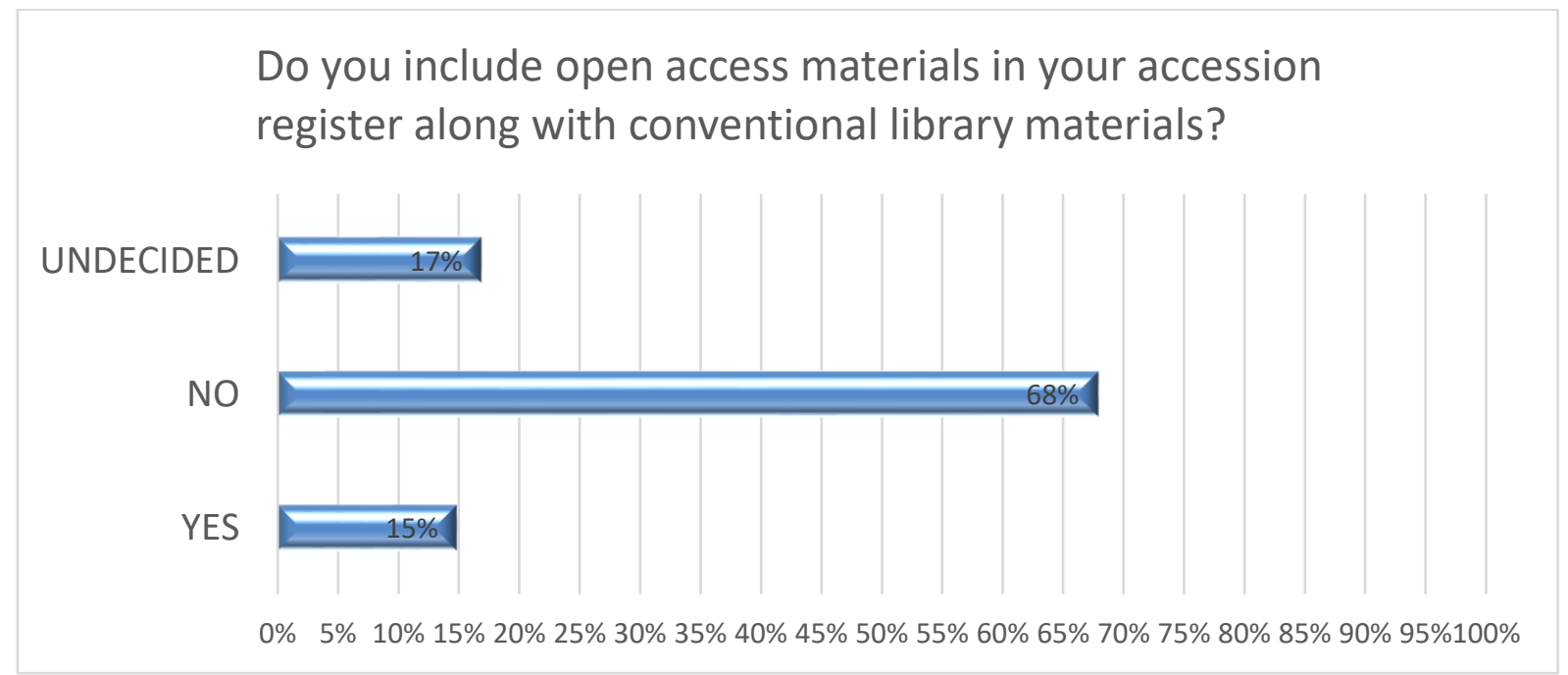

The response gotten from the respondents when asked if their library include open access materials in their accession register along with conventional library materials, indicate that $15 \%$ said Yes, $68 \%$ answered No, and $17 \%$ are Undecided.

Chart4: Do you catalogue and classify OAR as other library materials?

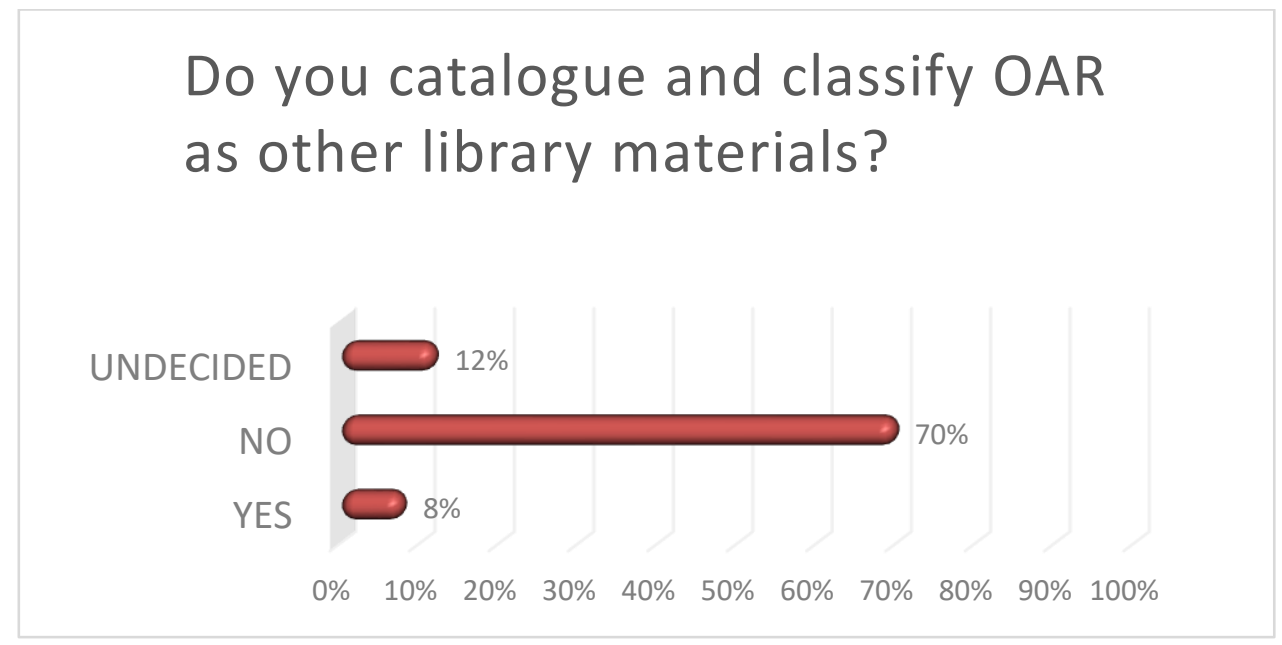

The response gotten from the respondents when asked if their library catalogue and classify OAR as other library materials, indicate that $8 \%$ said Yes, $70 \%$ answered No, and $12 \%$ are Undecided.

Chart 5: How do you make OAR available in your library? (You can indicate multiple options)

\section{How do you make OAR available in your library?}

They are online but Library have indexed/catalogued them

Library created link to facilitate their access

Library printed them into hardcopy

Library downloaded them and store them in Library LAN

Users search internet for it on their own

OA not available in the library

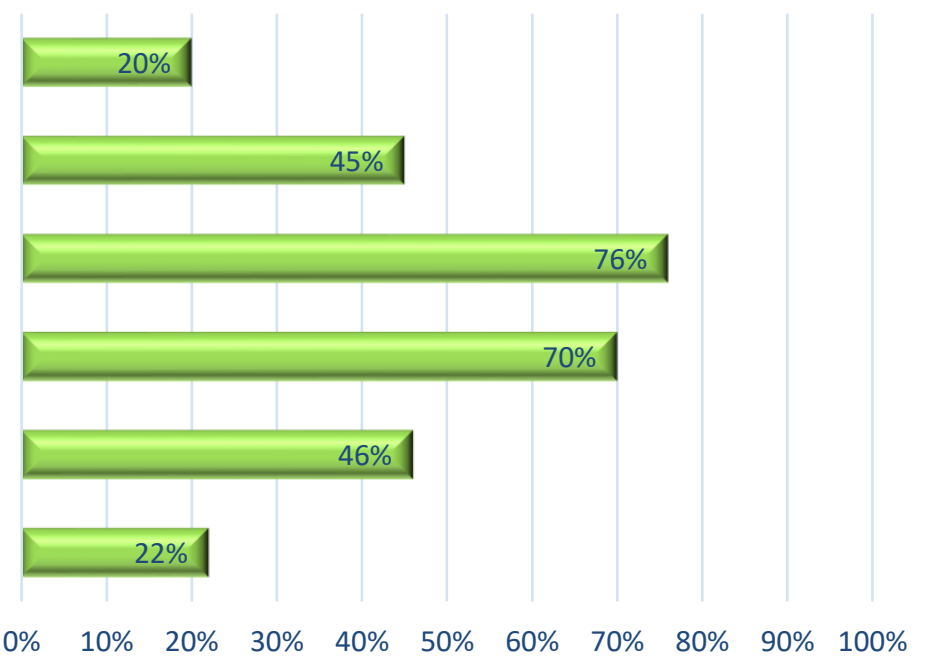




\section{Anyira Isaac Echezonam, et al.; International Journal of Advance Research, Ideas and Innovations in Technology}

The response gotten from the respondents when asked how they make open access resources available in their library, indicate that $20 \%$ they are online but they have indexed/catalogued them, $45 \%$ said they have created link to facilitate their access, $76 \%$ said they print them out as hardcopy, $70 \%$ said they download them and store them in local area network, $46 \%$ said that library users search for them on their own, $22 \%$ said OA in not available in their library.

Chart 6: Does your library index relevant OA titles in the library catalogues and discovery systems to ensure the end users can find them?

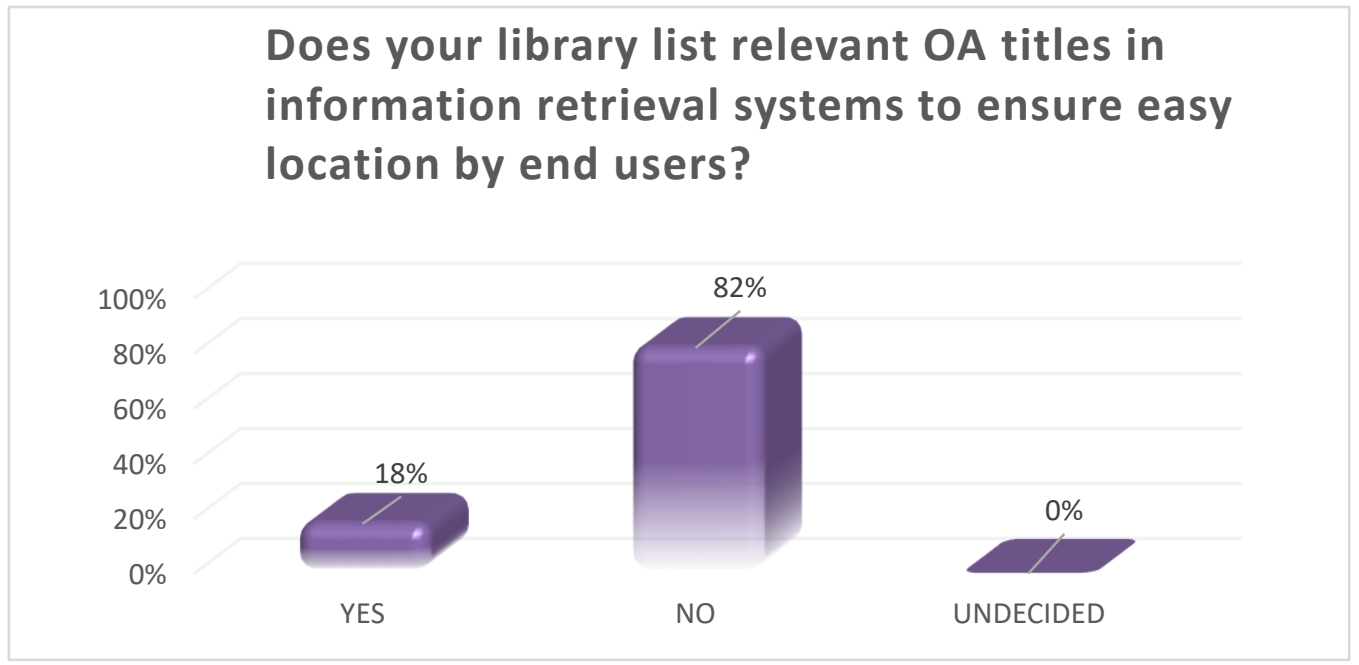

The response gotten from the respondents when asked if their library lists relevant OA titles in information retrieval systems to ensure easy location by end users indicate that $18 \%$ said Yes, $82 \%$ answered No.

Chart 7: Does you library have a collection development policy document?

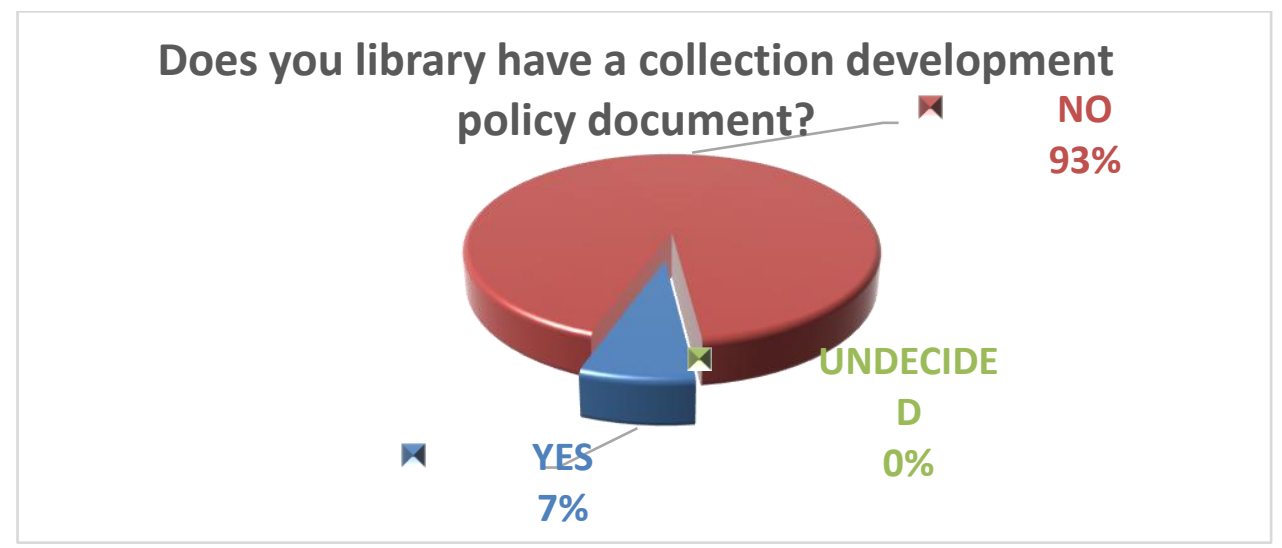

The response gotten from the respondents when asked if their library has a collection development policy document, indicate that $7 \%$ said Yes, while $93 \%$ answered No.

Chart 8: To what extent do you agree that a collection development policy document is key to OA integration?

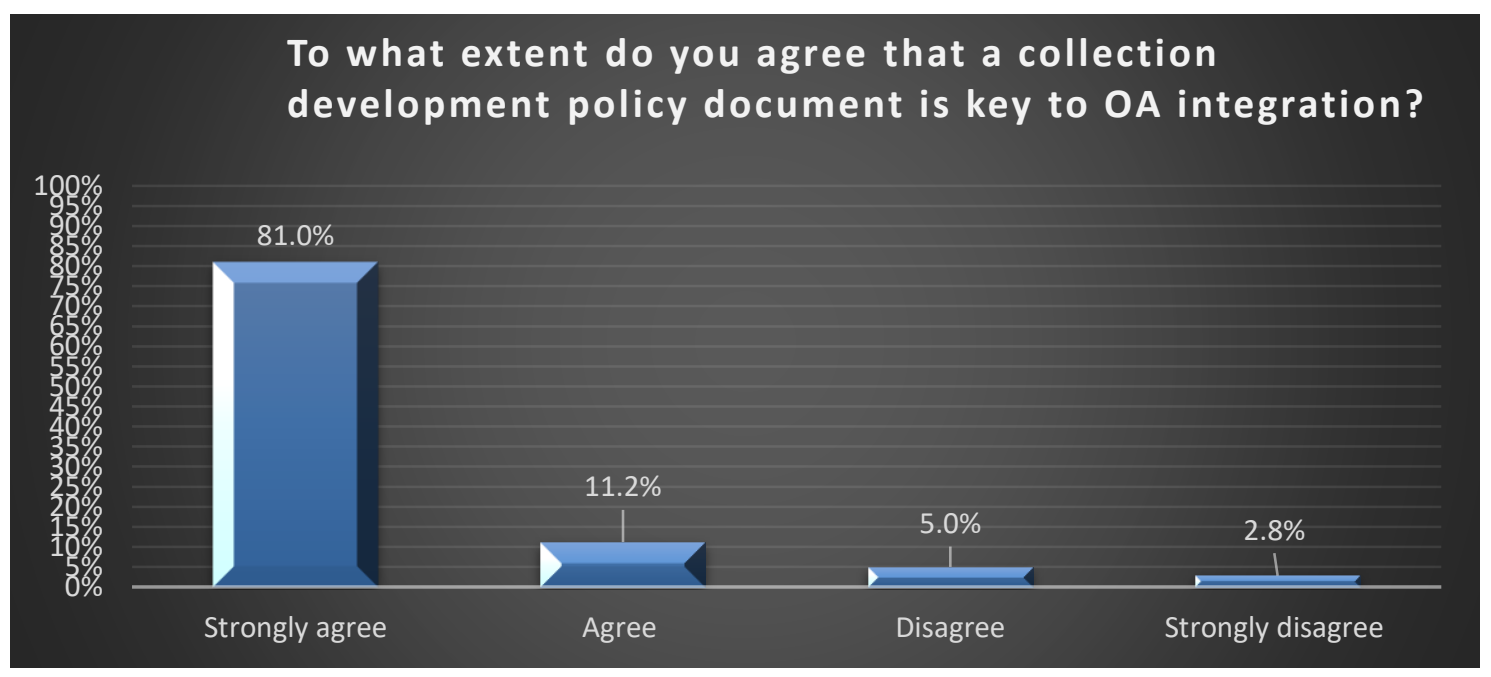




\section{Anyira Isaac Echezonam, et al.; International Journal of Advance Research, Ideas and Innovations in Technology}

The response gotten from the respondents when asked extent in which they agree that a collection development policy document is key to $\mathrm{OA}$ integration, indicate that $81 \%$ strongly agree, $11.2 \%$ agree, $5 \%$ disagree, $2.8 \%$ strongly disagree.

Chart 9: Are your library staff trained to develop skills to manage OA effectively?

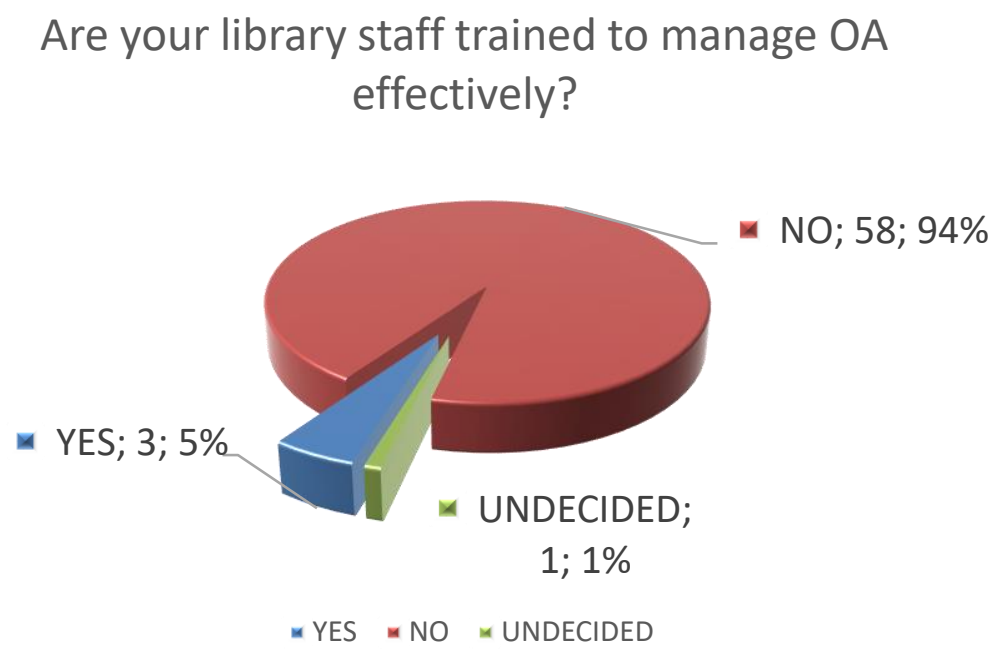

The response gotten from the respondents when asked if their library staff are trained to manage OA effectively, indicate that $5 \%$ said Yes, while $94 \%$ answered No and $1 \%$ is Undecided.

Chart 10: Do you agree that OA provides great opportunities to libraries to develop their collections?

\section{Do you agree that OA provides great opportunities to libraries to develop their collections?}

Strongly disagree $2.8 \%$

Disagree 5\%

Agree $11.2 \%$

Strongly agree $81 \%$
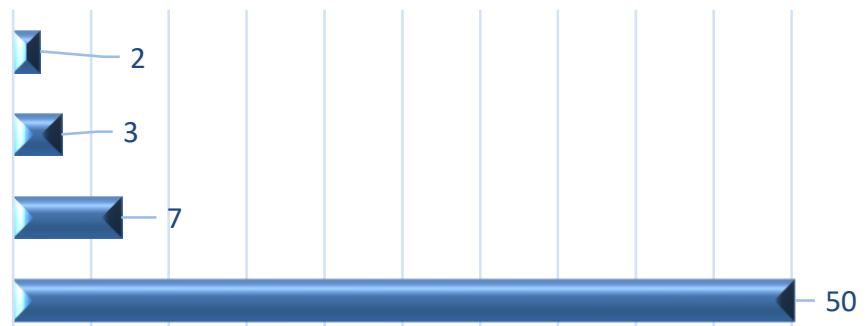

The response gotten from the respondents when asked extent in which they agree that OA provides great opportunities to libraries to develop their collections, indicate that $81 \%$ strongly agree, $11.2 \%$ agree, $5 \%$ disagree, $2.8 \%$ strongly disagree.

Chart11: Which of the following do you consider a challenge to OA integration in your library? (You can select more than one option)

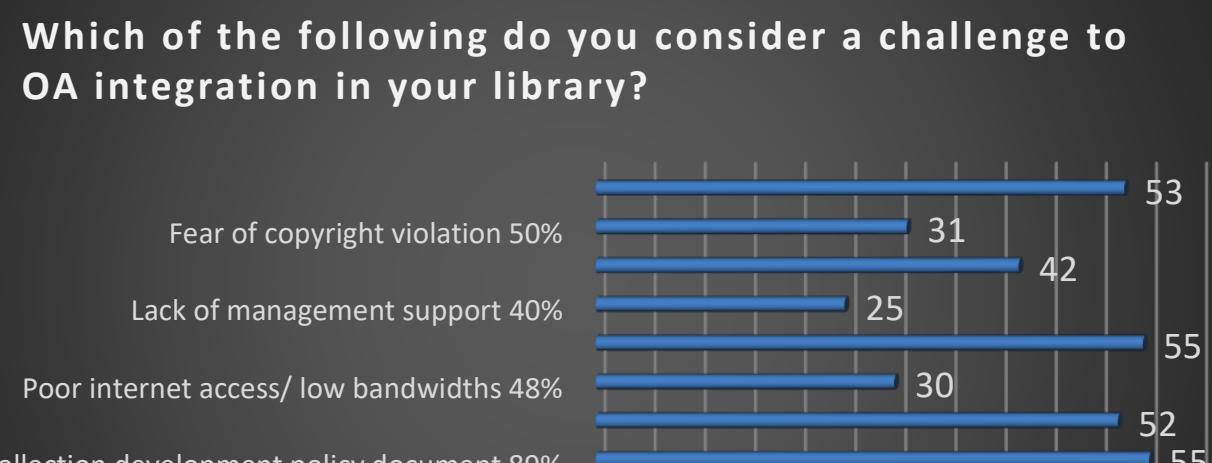




\section{Anyira Isaac Echezonam, et al.; International Journal of Advance Research, Ideas and Innovations in Technology}

The response gotten from the respondents when asked about the challenges to OA integration in their library, indicate poor electricity supply $85 \%$, Fear of copyright violation 50\%, Lack of funds $68 \%$, Lack of management support $40 \%$, Lack of knowledge and skills required for OA integration $88 \%$, Poor internet access/ low bandwidths $48 \%$, Lack of support from the head librarian $84 \%$, Lack of collection development policy document $89 \%$.

\section{CONCLUSION}

OAR brought about active collection development which adds ever increasing value to the library collection as well as provides exciting discovery of quality materials for library users. OAR can leverage collection development far beyond the norms of traditional library collection development practice. The present economic challenge in the country occasioned by the outbreak of Covid-19 Pandemic ravaging the world, has further brought to the fore the need for integration of OAR. It must be realized however, that the integration of OAR into collection development workflows, will take the library a little further from its traditional roles to more innovative functions. Training and skill acquisition to cope with the dynamics of OAR must be consolidated.

\section{RECOMMENDATIONS}

For effective integration of OAR into library collections development, the following strategies are recommended:

- Libraries should first and foremost, create a well-rounded collection development policy that makes OAR a core library material same as book and journals.

- Library staff should be equipped with relevant skills through training and retraining.

- Rather than purchasing expensive books and journals especially the foreign ones, libraries should "Harvest or Download" OAR relevant to them, package or repackage them, process them and make them available to their users as part of their collections.

- Funding authorities/ management should provide the library with funds and up-to-date ICTs necessary for OA project.

- Librarians should encourage the integration OAR and as quickly as possible, and adopt plans for transmission to a complete open access library.

- Libraries should be provided with uninterrupted fast speed internet access and power supply from solar power.

\section{REFERENCES}

[2] Anyira, I. \& Idubor, I. (2018). Open access resources: Panacea to improved library resources and services in Nigeria. International Journal of Advance Research, Ideas and Innovations in Technology, 4 (4), 890-895pp. Retrieved from https://www.ijariit.com/manuscripts/v4i4/V4I4-1477.pdf

[3] Anyira, I. \& Idubor, I. (2019). Open access resources: option for libraries in a challenged economy. A paper presented at the National Conference of the School Of Business Studies, Delta State Polytechnic Ogwashi Uku, On 18th -21st June, 2019.

[4] Anyira, I. \& Njoeteni, L. (2019). Improving the web presence and visibility of Delta State Polytechnics, Ogwashi-Uku, Ozoro, and Oghara. A paper presentation at the School of Engineering, Delta State Polytechnics, Ogwashi-Uku $4^{\text {th }}$ National Conference and Exhibition held 3-6 ${ }^{\text {th }}$ December, 2019.

[5] Association of European Research Libraries (2019). Open Access Books in Academic Libraries: How Can We Adapt Workflows \& Cost Management to an Open Scholarly Communications Landscape? Retrieved from https://libereurope.eu/blog/2019/07/26/open-access-books-in-academic-libraries-how-can-we-adapt-workflows-costmanagement-to-an-open-scholarly-communications-landscape/

[6] Budapest Open Access Initiative (2002). Read the Budapest Open Access Initiative. Retrieved from http://www.budapestopenaccessinitiative.org/read

[7] Gent University (2020). Open Access colours: gold, green, hybrid and more. Retrieved from https://onderzoektips.ugent.be/en/tips/00000461/

[8] Himmelstein, D., Romero, A., Levernier, J. (2018). Sci-Hub provides access to nearly all scholarly literature. Retrieved from https://www.st-va.ncbi.nlm.nih.gov/pmc/articles/PMC5832410/

[9] Horava, T. (2010). Challenges and possibilities for collection management in a digital age. Library Resources \& Technical Services, 54(3), 142-152.

[10] IFLA (2020). Call for Papers - Open Sessions: Acquisition and Collection Development for the IFLA World Library and Information Congress, Dublin, Ireland, August 15-21 2020. Available at https://www.ifla.org/acquisition-collectiondevelopment

[11] Mullen, L.B. (2010). Open Access and its Practical Impact on the work of Academic Librarians: Collection Development, Public Services, and the Library and Information Science Literature. Oxford : Chandos.

[12] Suber, P. (2003). Removing the Barriers to Research: An Introduction to Open Access for Librarians. College \& Research Libraries News, 64, pp. 92-94, 113.

[13] UNESCO (n.d.). what is open access? Retrieved from https://en.unesco.org/open-access/what-open-access

[14] United Nations Educational Scientific and Cultural Organization (2018) Global Open Access Portal: Nigeria. Retrieved from http://www.unesco.org/new/en/communication-and-information/portals-and-platforms/goap/access-by-region/africa/nigeria/ 